sequent publication. The conclusion is that a mechanism of sucrose synthesis was operating which was different from the simple reaction between glucose-1. phosphate and fructose shown in the equation. This is in agreement with the results of previous workers using intact leaves ${ }^{6}$ and algæ ${ }^{7}$.

The sucrose-forming activity of the crude pea extract was destroyed by heating for three minutes at $100^{\circ} \mathrm{C}$. The activity remained in the supernatant when the crude pea extract was centrifuged at $20,000 \mathrm{~g}$ for thirty minutes. The extract possessed negligible invertase activity. Sucrose synthesis was completely inhibited by $1 \times 10^{-4} M$ iodoacetate and $6.5 \times 10^{-3} M$ fluoride.

A detailed account of this work will be presented elsewhere. It is proposed to publish shortly results of experiments using a purified enzyme preparation.

I wish to express my indebtedness to Prof. C. S. Hanes and Dr. L. W. Mapson.

Financial support was provided by the Australian Commonwealth Scientific and Industrial Research Organization, and the work was continued during the tenure of a Broodbank Fellowship of the University of Cambridge.

Botany School, Cambridge. Oct. 22.

${ }^{1}$ Doudoroff, M., Kaplan, N., and Hassid, W. Z., J. Biol. Chem., 148, $67(1943)$.

Doudoroff, M., J. Biol. Chem., 151, 351 (1943).

s Doudoroff, M., Fed. Proc., 4, 241 (1945).

4 Bacon, J. S. D., and Edelman, J., Biochem. J., 48, 114 (1951).

${ }^{5}$ Bryson, J. L., and Mitchell, T. J., Nature, 167, 864 (1951).

Hassid, W. Z, and Putman, E. W. Fed. Proc, 11, 226 (1952).

${ }^{2}$ Calvin, M., and Benson, A. A., Science, 109, 140 (1949).

\section{Autoradiographic Detection of Sulphur-35 Synthesis by the Mucous Neck Cells of the Rat's Stomach}

TINCTORIAL and histochemical differences between the surface cells of the stomach and the mucous neck cells described by Bensley are now classical knowledge ${ }^{1}$; moreover, physiological and biochemical differences between dissolved mucin and visible mucin have been established ${ }^{2}$. The stomach secretion has also been found to contain a mucoprotein, the polysaccharide moiety of which was identified as mucoitin disulphuric acid ${ }^{3,4}$.

While studying the formation of the organic matrix of bones and teeth by autoradiographic mapping, some interesting pictures of the stomach were revealed after introduction of radiosulphur. Rats of 10 days of age were injected subcutaneously with a tracer dose of sulphur-35 separated isotope in the form of weak sulphuric acid, and they were sacrificed at various intervals thereafter. The tissues were fixed in a mixture of 95 per cent ethanol and neutral formaldehyde (3/1). After routine histological treat. ment, sections were cut and coated with fluid photographic emulsion to obtain autoradiographs by the inversion technique ${ }^{5}$.

In animals sacrificed one hour after the injection of sulphur-35, the stomach wall showed a fairly high Geiger-Müller count compared to other soft tissues. Autoradiographs exposed for a few days (Fig. 1) have revealed that there was a specific localization of the radiosulphur in the glandular portion of this organ,

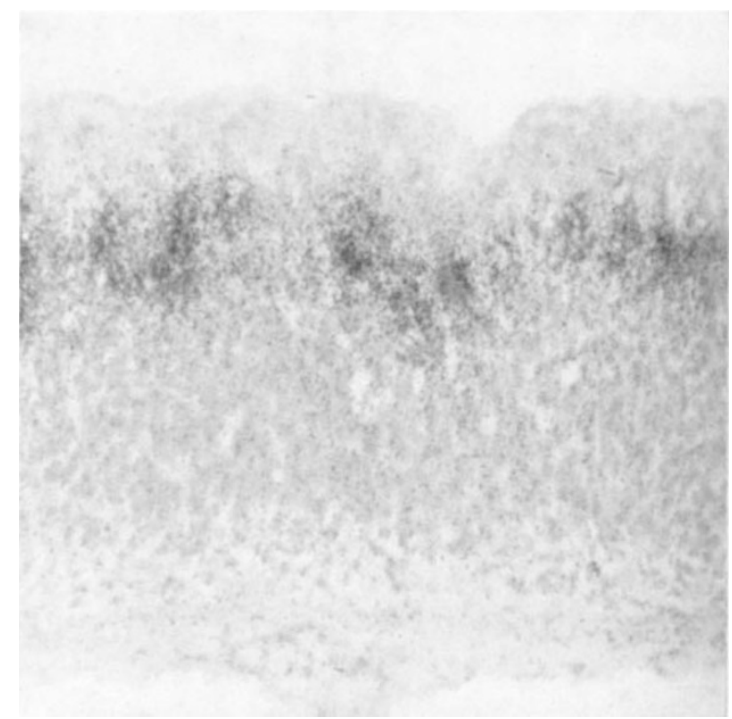

Fig. 1. Sulphur-35 autoradiograph of a portion of the mucosa of the glandular stomach in a 10-day old rat, showing the presence injection $\times 332$

at the level of the neck of the glands. The surface epithelium as well as the distal portion of the glands showed no autoradiographic image. In animals sacrificed $48 \mathrm{hr}$. after the introduction of tracer, no autoradiographic picture was visible over the mucosa; but streaks of mucin mixed with the chyme of the cavity exhibited radioactivity.

These experiments indicate that there is a chemical difference between the secretion of the surface cells and that of the mucous neck cells. These have the ability to synthesize rapidly an organic substance containing sulphur and retained by alcohol-formaldehyde fixation. Boström and Odeblad ${ }^{8}$ have recently demonstrated that, following an injection of radiosulphate, the uptake of sulphur-35 is highest in structures containing mucopolysaccharides. It is thus reasonable to conclude that the mucous neck cells produce a mucoprotein containing a sulphomucopolysaccharide, and that in comparable circumstances this substance is not present in the surface cells. The product of the mucous neck cells is totally excreted at the end of two days, and it is found in the chyme where it retains its identity after histological fixation. Work is in progress to establish comparisons between the various portions of the stomach and other regions of the gastro-intestinal tract.

I am indebted to Mrs. Cécile Bélanger for technical collaboration, and to the Medical Division of the National Research Council of Canada for a grantin-aid. The radioactive material was provided by Atomic Energy of Canada, Ltd.

LEONARD F. BÉlanger

Department of Histology and Embryology,

School of Medicine,

University of Ottawa,

Canada.

Aug. 24

${ }^{1}$ Soeborg-Ohlsen, A., C.R. Tr. Lab. Carlsberg (série chimique), 23, 329 (1941).

2 Glass, B. G. J., and Boyd, L. J., Gastroenterology, 12, 821 (1949).

${ }^{3}$ Levene, P. A., and Lopez-Suarez, J., J. Biol. Chem., 25, 511 (1916).

'Meyer, K., Smyth, E. M., and Palmer, J. W., J. Biol. Chem., 119 $73(1937)$

'Bélanger, L. F., Nature, 170, 625 (1952)

${ }^{\circ}$ Boström, H., and Odeblad, E., Anat. Rec., 115, 505 (1953) 